\title{
Epidemiological features of ruptured dissecting and saccular aortic aneurysms
}

\author{
S. TALBOT \\ M.B., B.S., M.R.C.P. \\ M. J. S. Langman \\ M.D., M.R.C.P.

\section{Department of Medicine, Nottingham General Hospital, Nottingham}

\begin{abstract}
Summary
An analysis based upon necropsy figures has been made of the frequency of deaths with dissecting aneurysms and ruptured fusiform or saccular aortic aneurysms. More deaths from these conditions were found at necropsies conducted on people dying suddenly in the community than in those dying in hospital.

Dissecting aneurysms were nearly all found to involve the thoracic segment of the aorta and were equally common in men and women whereas ruptured saccular and fusiform aneurysms were usually sited in the abdominal aorta and mainly occurred in men.

There was also a clear seasonal variation in death rates with ruptured and dissecting aneurysms. Death more commonly occurred with both types in the winter months.
\end{abstract}

\section{Introduction}

Hospital statistics suggest that ruptured or dissecting aortic aneurysms are rare causes of death, but such statistics are likely to te misleading when used as indices of prevalence because complications of aortic aneurysm usually cause rapid death.

A comparison has therefore been made between some pathological and epidemiological characteristics of the condition in patients dying in hospital and in those dying suddenly in the community in whom ruptured saccular or dissecting aneurysms were found to be present.

\section{Method}

Hospital necropsy records were examined for the years 1960-70 inclusive at the Nottingham City and General Hospitals, the two district general hospitals serving the surrounding population of over half a million people. In addition, the records of all coroner's necropsies carried out in individuals dying suddenly outside hospital in the Nottingham area were examined similarly. In all patients considered by the pathologist to have died of ruptured aortic aneurysm or dissection, the age, sex, date of death and site of aneurysm were noted. A pathological diagnosis of dissecting aneurysm was accepted provided that there was clear evidence of separation, whatever its extent, within the aortic wall. Patients were classified separately if a saccular or fusiform aneurysm had keen thought to ke present and then complicated by rupture.

The site of dissection was descrited as proximal or distal thoracic or abdominal according to whether the intimal tear was sited, respectively, proximal to the innominate artery, distal to the innominate artery but above the diaphragm, or below the diaphragm.

\section{Results}

Two hundred and fifty patients were coded as having dissecting aneurysms of the aorta during the time period under review. Thirty-eight of these, who were recorded as having pre-existing saccular aneurysms with dissection at the edge, were excluded from the analysis as were sixteen in whom aortic rupture had occurred but whose detailed records dide not specifically mention the presence of dissection.

Table 1 shows details of the remaining 196 patients, divided according to source of ascertainment, from hospital deaths or Nottingham community deaths and also according to the patient's sex, age and the site of rupture. One hundred and twentyfour $(63.8 \%)$ of the total group were found by examination of coroner's necropsy records. In 105 of these the dissection was sited in the proximal thoracic segment of the aorta, and seventy-six of those examined were women. By contrast only seventy-two $(36.7 \%)$ of the total group were ever admitted to hospital; less than half $(44.4 \%)$ of the dissections in these patients were sited in the proximal thoracic aorta, and it contained over twice as many women as men. Patients admitted to hospital also tended to ke younger than those dying in the community.

Table 2 shows figures set out similarly for patients with ruptured saccular aneurysms (including the thirty-eight excluded from the previous analysis who had marginal dissections with pre-existing saccular aneurysms). Slightly more than half $(57 \cdot 7 \%)$ of the patients died suddenly in the community, the aneurysm was sited in any part of the thoracic aorta in only twenty-six $(21 \%)$ of these, and over half $(70.2 \%)$ of the sudden death group were men. The hospital death group also consisted predominantly of men $(64.8 \%)$ and only fifteen $(16.1 \%)$ of the 
TABLE 1. Dissecting aneurysm deaths

\begin{tabular}{|c|c|c|c|c|c|c|c|}
\hline & \multicolumn{3}{|c|}{ In the community } & \multicolumn{3}{|c|}{ In hospital } & \multirow{2}{*}{$\begin{array}{c}\text { Overall } \\
\text { total }\end{array}$} \\
\hline & $\overline{\text { Men }}$ & Women & Total & $\overline{\text { Men }}$ & Women & Total & \\
\hline \multicolumn{8}{|l|}{$\overline{\text { Site }}$} \\
\hline Proximal thoracic & 37 & 68 & 105 & 21 & 11 & 32 & 137 \\
\hline Distal thoracic & 9 & 4 & 13 & 26 & 11 & 37 & 50 \\
\hline Abdominal & 1 & 2 & 3 & 1 & 0 & 1 & 4 \\
\hline Multiple or unknown & 1 & 2 & 3 & 1 & 1 & 2 & 5 \\
\hline Total & 48 & 76 & 124 & 49 & 23 & 72 & 196 \\
\hline Mean age (years) & $68 \cdot 6$ & $76 \cdot 8$ & & $59 \cdot 1$ & $67 \cdot 5$ & & \\
\hline
\end{tabular}

TABLE 2. Fusiform and saccular aneurysm deaths

\begin{tabular}{|c|c|c|c|c|c|c|c|}
\hline & \multicolumn{3}{|c|}{ In the community } & \multicolumn{3}{|c|}{ In hospital } & \multirow{2}{*}{$\begin{array}{c}\text { Overall } \\
\text { total }\end{array}$} \\
\hline & $\overline{\text { Men }}$ & Women & Total & Men & Women & Total & \\
\hline \multicolumn{8}{|l|}{$\overline{\text { Site }}$} \\
\hline Proximal thoracic & 2 & 3 & 5 & 2 & 0 & 2 & 7 \\
\hline Distal thoracic & 12 & 9 & 21 & 4 & 9 & 13 & 34 \\
\hline Abdominal & 68 & 25 & 93 & 49 & 23 & 72 & 165 \\
\hline Multiple & 1 & 4 & 5 & 4 & 0 & 4 & 9 \\
\hline Total & 83 & 41 & 124 & 59 & 32 & 91 & 215 \\
\hline Mean age (years) & $69 \cdot 7$ & $76 \cdot 0$ & & $68 \cdot 7$ & $75 \cdot 8$ & & \\
\hline
\end{tabular}

ninety-one aneurysms occurring in patients in this group were sited in the thoracic aorta.

Details of the seasonal incidence of dissecting and saccular aneurysms are given in Figs. 1 and 2. Both hospital and community deaths tended to te commoner in winter than in summer months and the significance of this trend was assessed mathematically by an extension of a test for randomness of direction within the year (Stephens, 1969). Briefly this test is based upon a consideration of the year as a circle with each of the months acting as individual centrifugal forces from a central part, the strength of each of the forces being in proportion to the observed number of cases of the disease within the month. There was a highly significant trend in mortality patterns for both types of aneurysm $\left(\chi^{2}=13.9\right.$, $P=0.001$ and $\chi^{2}=11 \cdot 7, P=0.001$ for dissecting, and for saccular or fusiform aneurysms respectively).

\section{Discussion}

The results obtained in this survey show that any measurement of the frequency of death with ruptured aortic aneurysm which is based upon hospital statistics is likely to be a considerable underestimate. Comparable figures from elsewhere are hard to obtain. Dissecting aneurysms were found at necropsy examination in $1.1 \%$ of cases of sudden non-violent death in the San Francisco community (Mote \& Carr, 1942). By contrast in another survey conducted in Galveston, Texas (Brindley \& Stembridge, 1956), saccular or fusiform aneurysms were found in $3.54 \%$ of hospital necropsies and dissecting aortic aneurysms in a further $0.44 \%$; between a half and a third of all

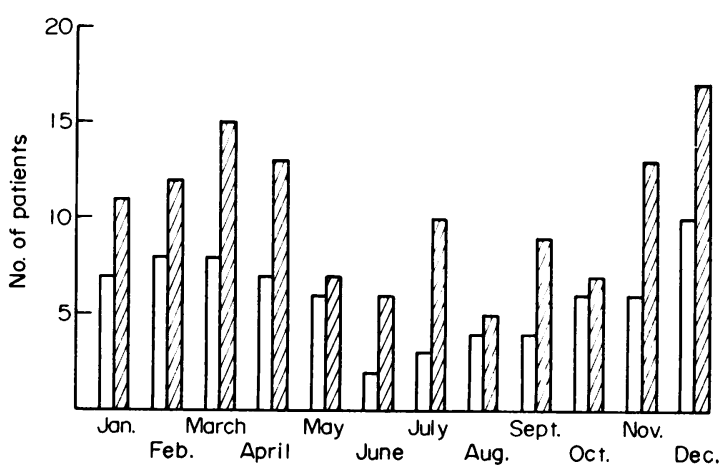

Fig. 1. Seasonal incidence of deaths from dissecting aneurysms. Open columns, deaths in hospital; diagonally hatched columns, deaths in the community.

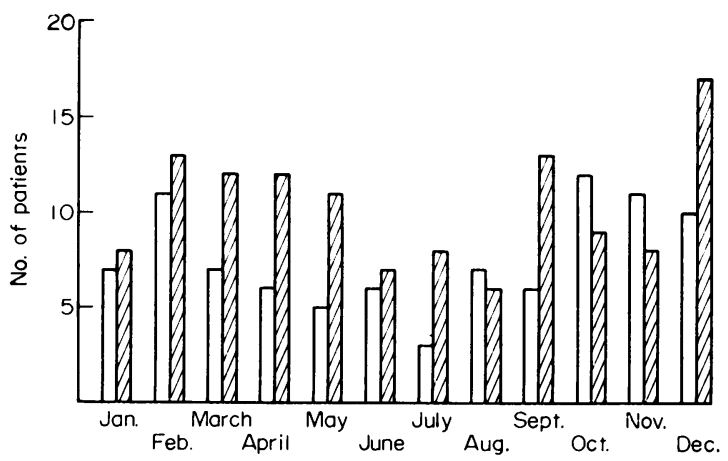

FIG. 2. Seasonal incidence of ruptured fusiform/saccular aneurysms. Open columns, deaths in hospital; diagonally hatched columns, deaths in the community. 
saccular or fusiform aneurysms were then found to have ruptured.

It has previously been found that many proximal dissections rupture into the pericardium (Hirst, Johns \& Kime, 1958; Brindley \& Stembridge, 1956) and the high proportion of community deaths with proximal dissecting aortic aneurysm in our series could well be due to early sudden death with this complication. Although there were equal overall proportions of men and women with dissecting aneurysm in the present group, women were more likely to die in the community, probably because they tended to have proximal dissections more often than men and therefore were prone to sudden death from rupture.

A very high proportion of fusiform or saccular aneurysms, mostly in men, were found in the abdominal aorta, and few were detected in the thoracic segment. There is no means of knowing whether the site differences for dissecting classified in ISC category 441 , and for saccular or fusiform aneurysms classified in ISC category 442 reflect a real difference in distribution or systematic variations in classification. Limited degrees of dissection could well occur at the edges of simple aneurysms and make classification difficult, but it seems unlikely that the gross variations in site incidence of aneurysms of dissecting and non-dissecting type could be ascribed simply to variations in classification.

The seasonal variation noted in deaths with aneurysms is similar to that noted for a large variety of diseases both vascular and non-vascular including ischaemic heart disease (Dunnigan, Harland \& Fyfe, 1970) and peptic ulcer (Jamieson, 1947; Breen \&
Grace, 1962; Langman, 1964). The same trend can also be detected in figures obtained for admissions with aneurysm in the Hospital In-patient Enquiry (1967). The causes of these variations are unknown. It is known, however, that blood pressure tends to rise in the winter (Rose, 1961) and associations have been noted between preceding hypertension and liability to dissecting and ruptured saccular aneurysm (Hirst et al., 1958; Brindley \& Stembridge, 1956).

\section{Acknowledgments}

We are grateful to Dr G. F. M. Hall and to Dr R. E. Cotton for allowing us to examine the necropsy reports, and to Professor M.A. Stephens for the mathematical analysis.

\section{References}

Breen, F.J. \& Grace, W.J. (1962) Bleeding peptic ulcer. Seasonal variation. American Journal of Digestive Diseases, 7, 727.

Brindley, P. \& Stembridge, V.A. (1956) Aneurysms of the aorta, a clinicopathological study of 369 necropsy cases. American Journal of Pathology, 32, 62.

DunNigan, M.G., Harland, W.A. \& FyFe, T. (1970) Seasonal incidence and mortality of ischaemic heart disease. Lancet, ii, 793.

Hirst, A.E., Johns, V.J. \& KIme, S.W. (1958) Dissecting aneurysm of the aorta, a review of 505 cases. Medicine, 37, 217.

JAMIESON, R.A. (1947) Perforated peptic ulcer. British Medical Journal, 2, 289.

LANGMAN, M.J.S. (1964) The seasonal incidence of bleedinge from the upper gastrointestinal tract. Gut, 5, 142.

MoTe, C.D. \& CARR, J.L. (1942) Dissecting aneurysm of the aorta. American Heart Journal, 24, 69.

Rose, G. (1961) Seasonal variation in blood pressure in man. Nature, 189, 235.

STEPHENS, M.A. (1969) Tests for randomness of directions against two circular alternatives. Journal of the American Statistical Association, 62, 280. 